\title{
Comparison of Genetic Algorithm and Harmony Search Method for 2D Geometry Optimization.
}

\author{
Mohammad Ghozi ${ }^{1,}{ }^{*}$ and Anik Budiati ${ }^{2}$ \\ ${ }^{1,2}$ Bhayangkara Surabaya University, Engineering Department, Surabaya, Indonesia
}

\begin{abstract}
There are many applications of Genetic Algorithm (GA) and Harmony Search (HS) Method for solving problems in civil engineering design. The question is, still, which method is better for geometry optimization of a steel structure. The purpose of this paper is to compare GA and HS performance for geometric optimization of a steel structure. This problem is solved by optimizing a steel structure using GA and HS and then comparing the structure's weight as well as the time required for the calculation. In this study, GA produced a structural weight of 2308.00 $\mathrm{kg}$ to $2387.00 \mathrm{~kg}$ and HS scored $2193.12 \mathrm{~kg}$ to $2239.48 \mathrm{~kg}$. The average computational time required by GA is 607 seconds and HS needed 278 seconds. It concludes that HS is faster and better than GA for geometry optimization of a steel structure.
\end{abstract}

\section{Introduction}

The Genetic Algorithm (GA) method has been the designer's tool of many steel structures $[1,2]$. GA was developed and combined with chromosome repairing strategy on solving size optimization of steel structures [7]. On the other hand, Harmony Search (HS) came with a robust performance for determining the size optimization of steel structures [46], [8-9]. Both strategies are powerful for solving size optimization problems with minimization objective function due to several engineering constraints. With advantages of both methods, it is important to compare the performance between GA and HS especially for solving geometry optimization of a steel structure.

\section{Methods}

Methods used in this paper will be divided into three-part as 1) Research Method, 2) Steel Structure Model, and 3) Objective function. In the research method, there will be described the method used to solve the problem in this paper. The structure model description also will be explained and then the objective function of the optimization problem is outlined in the next subchapter.

\footnotetext{
* Corresponding author: mghozi@ubhara.ac.id
} 


\subsection{Research Method}

The aim of this research is to compare the best method between Genetic Algorithm (GA) and Harmony Search (HS) for 2D steel structure geometric optimization. The scopes of this research are the best weight and fastest computing time between GA and HS for optimizing one geometric structure model. This research is initiated by literature study, followed by deploying GA and HS to optimize the geometric structure model. Each method runs 10 times optimization process for accommodating natural behaviour of both methods. The Finite element method is organized to calculate stress and joint deflection [3]. Analysing data of objective function plot, weight and computing time are then proceed. The research method's flowchart is then shown in Fig. 1

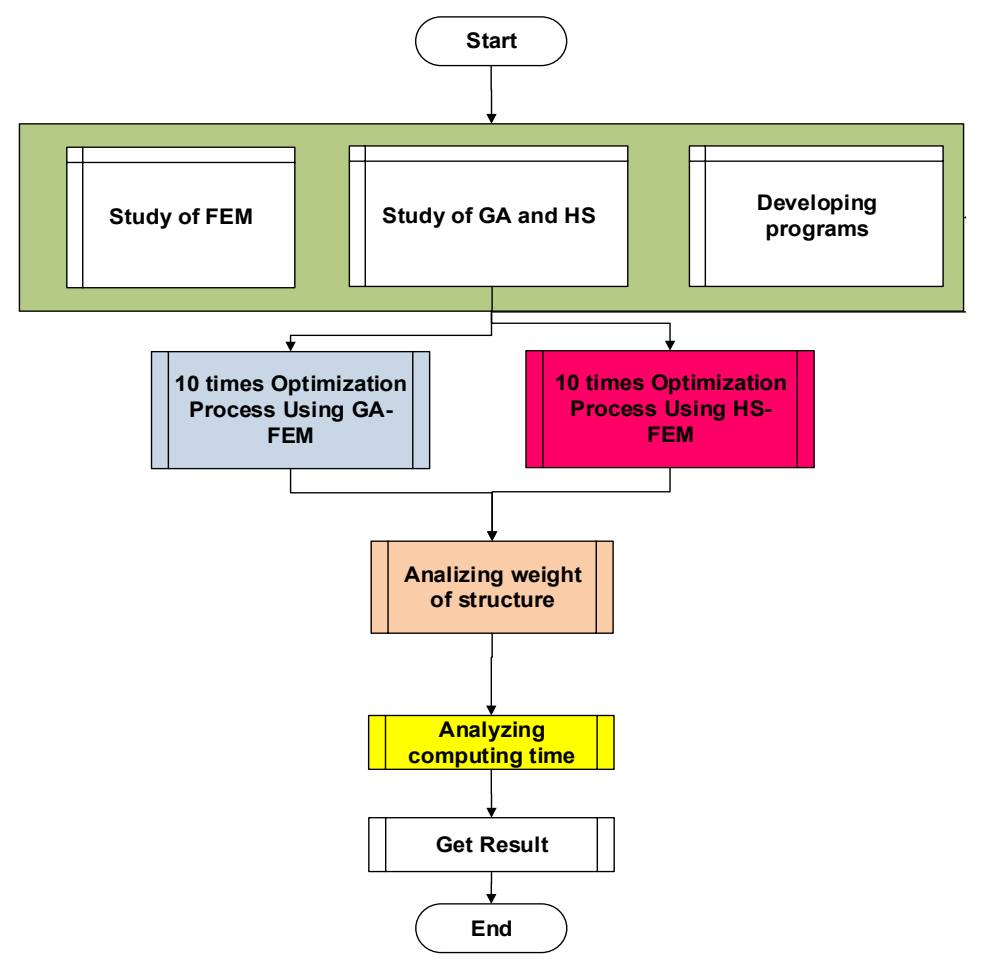

Fig. 1. Flowchart of Research Method

The GA follows flowchart as described in [7] and the HS uses the program as described in $[8,9]$. The FEM deployed in this research is developed according to the theory as described in [3]. Flowchart of GA and HS can be seen in Fig. 2. The parameters used by GA method in this paper are Generation $=100$, Population $=100$, Mutation Probability $=0.05$, Crossover Probability $=0.85$, Roulette Wheel Mode as Selection and Elitism $=10 \%$. HS method uses Pitch Adjusting Rate $=0.5$, Harmony Memory Size $=30$, Harmony Memory Considering Rate $=0.95$, Iteration $=10000$. The optimization process uses PC with Intel Core i5 $24003.1 \mathrm{GHz}$ processor, $8 \mathrm{~GB}$ DDR3 memory and AMD R7 200 series 2GB DDR3 as VGA Card. 


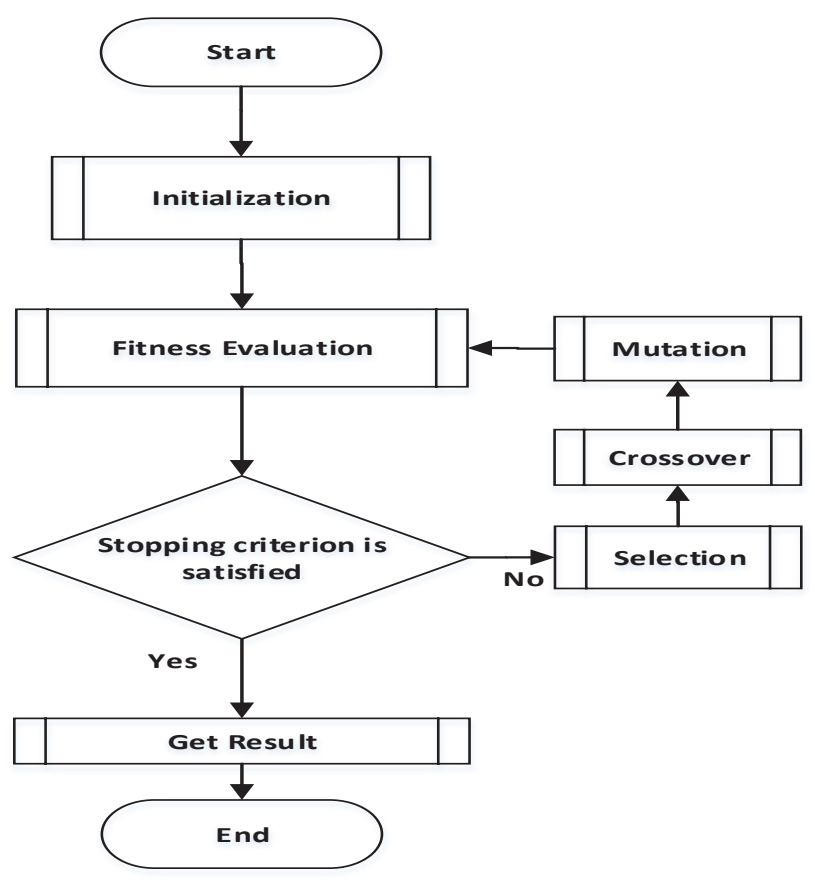

(a)

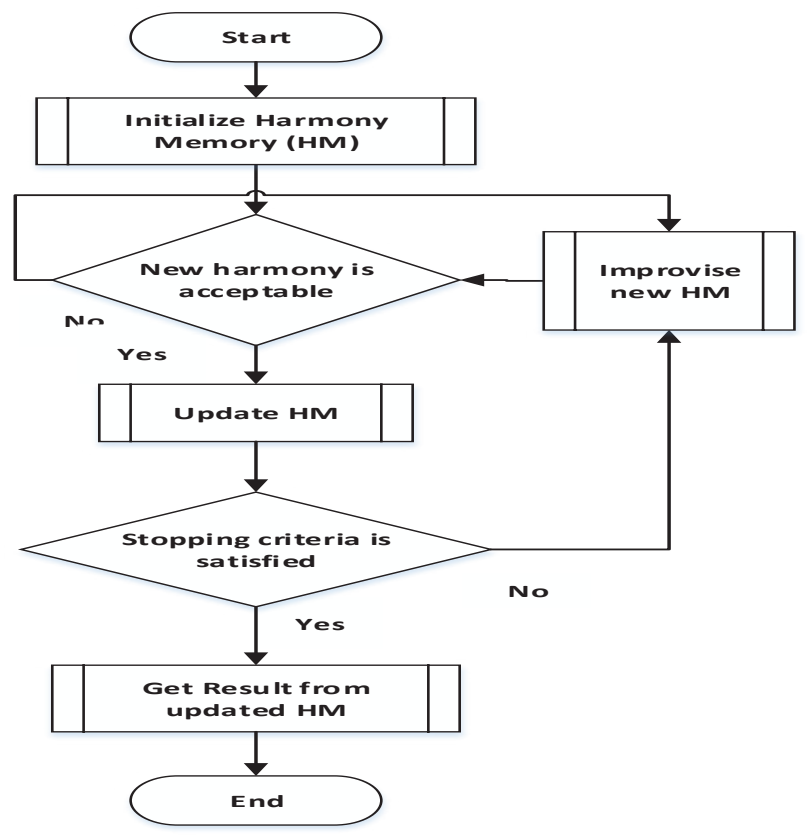

(b)

Fig. 2. Flowchart of: (a) GA [7], (b) HS [8] 


\subsection{Steel Structure Model}

The structure model used in this paper is a 2D structure with 10 elements and 6 joints [2]. Vertically downward loads of 100 kips $(445.374 \mathrm{kN})$ are applied on joint 2 and 4 (see Fig.3). The structure model data are Modulus of Elasticity, $\mathrm{E}=1 \times 10^{4} \mathrm{ksi}\left(6.89 \times 10^{4} \mathrm{MPa}\right)$, $\rho=0.10 \mathrm{lb} /$ in $\left(2,770 \mathrm{~kg} / \mathrm{m}^{3}\right)$. The allowable maximum stress is $25 \mathrm{ksi}(172.25 \mathrm{MPa})$ and the allowable joint deflection is 2 inch $(50.8 \mathrm{~mm})$. The available cross section areas are 10.45, $11.61,12.83,13.74,15.35,16.90,16.96,18.58,18.90,19.93,20.19,21.80,22.38,22.90$, $23.41,24.77,24.96,25.03,26.96,27.22,28.96,29.61,30.96,32.06,33.03,37.03,46.58$, 51.41, 74.19, 87.09, 89.67, 91.61, 99.99, 103.22, 109.03, 121.29, 128.141, 141.93, 147.74, 170.96, 193.54 and 216.12 (in cm unit). The allowable moved joints are joint 1 and 3.

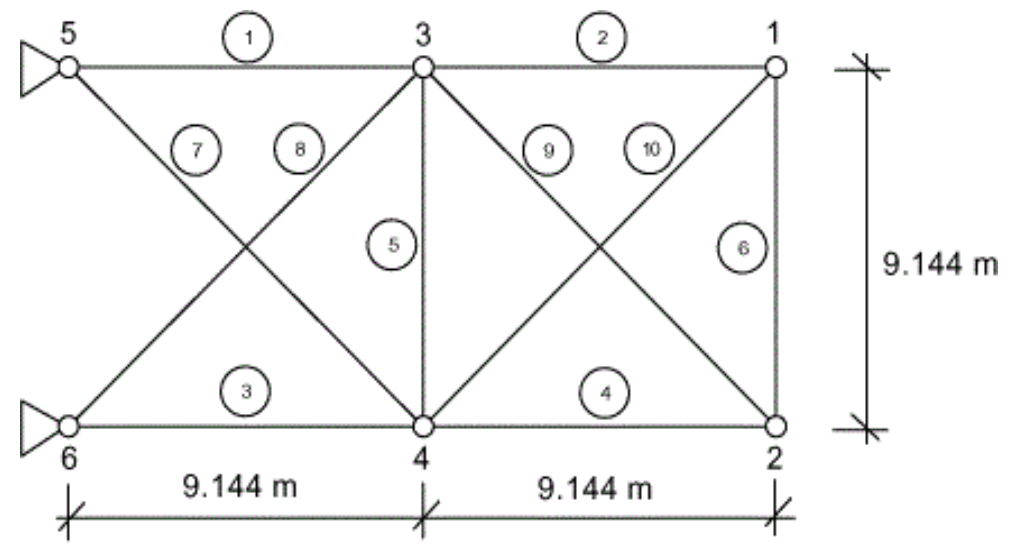

Fig. 3. Structure Model [2].

\subsection{Objective Function}

The objective function of optimization process in this research is:

$$
\text { Minimize } W=\sum \rho 1_{\mathrm{e}} A_{\mathrm{e}}
$$

Subjected to :

$$
\begin{aligned}
& \text { Stress } \quad \sigma_{e} \leq \sigma_{\max } \\
& \text { Deflection } \quad \Delta_{\mathrm{j}} \leq \Delta_{\max }
\end{aligned}
$$

Where :

$W=$ weight of structure $(\mathrm{kg}), \rho=$ unit weight of steel, $1_{\mathrm{e}}=$ length of element, $A_{\mathrm{e}}=$ area of

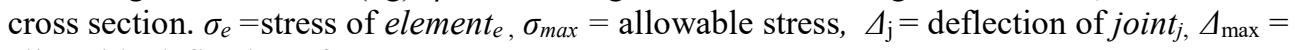
allowable deflection of joint $j$.

Penalty function strategy is used in this research. The penalty functions are :

$$
\begin{aligned}
& S c_{e}=1 \text { if } \sigma_{e} \leq \sigma_{\max } \text { or } S c=0 \text { if } \sigma_{e} \leq \sigma_{\max } \\
& D c_{j}=1 \text { if } \Delta_{\mathrm{j}} \leq \Delta_{\max } \text { or } S c=0 \text { if } \Delta_{\mathrm{j}} \leq \Delta_{\max }
\end{aligned}
$$


And the fitness equation is :

$$
\text { Fitness }_{c}=W+10\left(\sum S c_{e}\right)+100\left(\sum D c_{j}\right)
$$

Where $:$ Fitness $_{c}=$ Fitness value of chromosome $_{c}$

\section{Result and Discussion}

The 10 times optimization process using GA and HS have already conducted this research. HS produced structure's weight $2193.12 \mathrm{~kg}$ and GA got $2308.00 \mathrm{~kg}$ as best weights (see Table 1). This means HS can produce $4.9 \%$ lighter than GA's best weight. For obtaining $2500 \mathrm{~kg}$ as optimum weight [2], HS requires 890 until 1781 iterations. GA demands 1900 to 4500 evaluations for finding $2500 \mathrm{~kg}$ as optimum weight (see Fig. 4). This concludes that HS is $53 \%$ to $60 \%$ faster than GA.

Table 1. Comparison of weight and computational time between GA and HS.

\begin{tabular}{|c|c|c|c|c|}
\hline & \multicolumn{2}{|c|}{ GA Method } & \multicolumn{2}{c|}{ HS Method } \\
\hline Section & Weight (kg) & $\begin{array}{c}\text { Time } \\
\text { (second) }\end{array}$ & Weight (kg) & $\begin{array}{c}\text { Time } \\
\text { (second) }\end{array}$ \\
\hline Best & 2308.00 & 602 & 2193.12 & 268 \\
\hline Average & 2361.50 & 607 & 2213.22 & 278 \\
\hline Maximum & 2387.00 & 615 & 2239.48 & 289 \\
\hline
\end{tabular}

The GA and HS trajectory's objective functions are then displayed in Fig. 4.

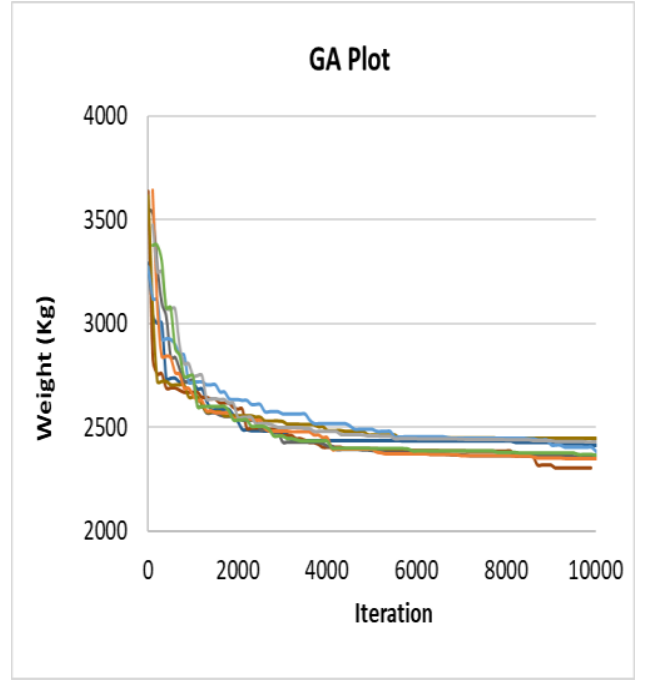

(a)

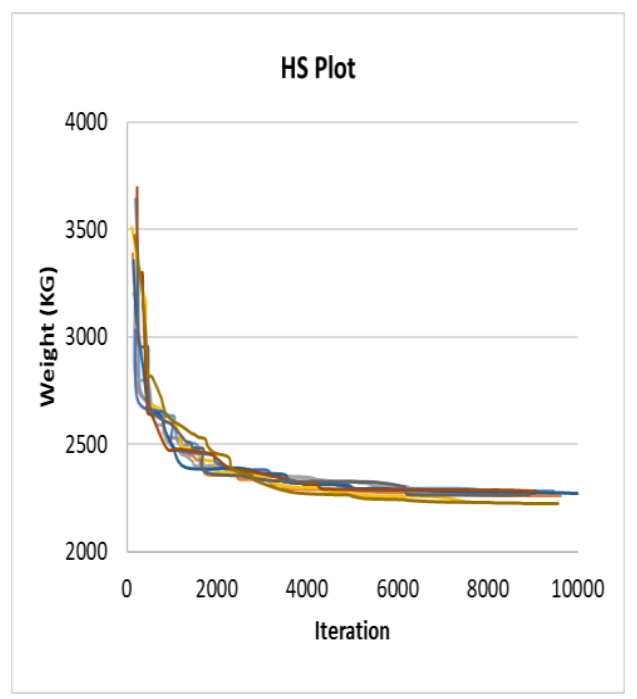

(b)

Fig. 4. Objective function plot: (a) GA's Plot; (b) HS's Plot. 


\section{Conclusion}

Comparison of GA and HS performance for geometry optimization of a steel structure has been implemented in this project. The comparison is overcome by optimizing one steel structure model using GA and HS and then comparing the weight of the structure. The time required for the computation is also be compared. GA produced structure's weight 2308.00 $\mathrm{kg}$ to $2387.00 \mathrm{~kg}$ and HS scored $2193.12 \mathrm{~kg}$ to $2239.48 \mathrm{~kg}$. The GA's average computation time is 607 seconds and HS's time is 278 seconds. It is concluded that HS is $53 \%$ faster than GA and HS also yields a lightweight steel structure of $4.9 \%$ than GA for geometric optimization of a steel structure.

This research was financially supported by Competitive Research Grant Committee of Bhayangkara Surabaya University, 2016.

\section{References}

1. D.E. Goldberg, Evolutionary Algorithm In Search, Optimization and Machine Learning, (Addition Wesley Publishing Co. Inc, USA, 1989)

2. S. Rajeev, C.S. Krishnamoorthy, Jour. Stru. Eng., 118 (1992).

3. R. Cook, Finite Element Modeling for Stress Analysis, (John Wiley \& Sons, USA, 1995)

4. Z.W. Geem, H.K. Joong, G.V. Loganathan, Sim. 76 (2001)

5. A.J. Khalifa, Design Optimization Of Steel Framed Structures To AISC-LRFD Using Harmony Search Algorithm, (Gaza Islamic University, Gaza, 2011)

6. S.A. Patil, D. A. Patel, Int. Jour. Eng. Sci. Inn. Tech., 2 (2013)

7. A. Budiati, M. Ghozi, Acad. Res. Int., 4, 493 (2013)

8. M. Ghozi, Acad. Res. Int., 5, 52 (2014)

9. M. Ghozi, P. Suprobo, Int. Jour. App. Eng. Res., 10, 33206 (2015) 